\title{
SCiP at 35: An idiosyncratic history of the Society for Computers in Psychology
}

\author{
CHRISTOPHER R. WOLFE \\ Miami University, Oxford, Ohio
}

\begin{abstract}
SCiP history may be divided into three eras: the Paleozoic (1971-1982), the Mesozoic (1982-1994), and the Cenozoic (1994-present). Following a list of Secretary-Treasurers, a list of all SCiP Presidents is provided in Table 1. Next I present personal highlights, including the first symposium on psychology and the World-Wide Web; David Rumelhart's mathematical explanation of connectionism; and Stevan Harnad's discussion of "freeing" the journal literature. I observe that a small conference is becoming more intimate and that much of our mission involves figuring out how to conduct high-quality scientific research with consumer-grade electronics. I argue that we are an increasingly international organization, that graduate students are welcome, and that we should become more inclusive in the areas of gender and ethnicity and should make membership more meaningful. I conclude by looking ahead and attempting to predict the future.
\end{abstract}

\section{My Involvement with SCiP}

The Society for Computers in Psychology (SCiP) has played an important role in my career for a long time. In 1989, I was a newly minted PhD with a tenure track job and extra responsibilities for computing when I attended my first meeting of the Society. Past President Joe Sidowski gave a memorable slide show on the history of the Society where, if memory serves, he inexplicably exhibited the rump of a rhesus monkey.

I had learned about SCiP as a graduate student from my friend and office mate at the University of Pittsburgh, the late Tim Post, who was the first recipient of what is now the Castellan Award for the best student paper. He had won a subscription to the Psychonomic Society journal Behavior Research Methods, Instruments, \& Computers (formerly Behavior Research Methods \& Instrumentation, now simply Behavior Research Methods), which has played a special role in the history of SCiP, and has been important for me personally. The late John Castellan himself edited my first journal publication in BRMIC. In that manuscript, I informally referred to a system as having a "steep learning curve." Castellan gently reminded me that for more than a century scientists had plotted time on the $x$-axis and percent correct on the $y$-axis, making a steep learning curve an indication of rapid learning. He told me that data on actual learning curves would be nice if I had it, and we speculated that the common misusage might have something to do with the image of a learner struggling up a steep hill. I dropped the informal reference from my manuscript and came away appreciating a person who embodied both high standards and compassion.

Correspondence concerning this article should be addressed to C. R. Wolfe, Western College Program, Miami University, Oxford, OH 45056 (e-mail: wolfecr@muohio.edu).

\section{The Paleozoic Era (1971-1982): The NCUOLCP Years}

The first 20 years of SCiP history are captured in an enjoyable article by former President and BRMI/BRMIC editor Joseph Sidowski entitled "Past, Present, and Future of the Society for Computers in Psychology" (Sidowski, 1990). As Sidowski explains, in 1971, with encouragement from the National Science Foundation, Donald Tepas set out to organize a national conference on the use of networked computers in psychology. Sidowski agreed to publish a special issue of $B R M I$ dedicated to the conference proceedings, and 27 conference papers were published in 1972. Tepas and the steering committee decided to hold the meeting the day before the Psychonomic Society meeting, in the same city, in order to improve attendance, a practice that has served the society very well for 35 years. Thus the first meeting of the National Conference on the Use of On-Line Computers in Psychology (NCUOLCP) was held on the campus of St. Louis University on November 10, 1971.

\section{The Mesozoic Era (1982-1994): A Euphonious Acronym}

The name of the organization was apparently a perennial topic of discussion until the present name, the Society for Computers in Psychology, was adopted in 1982. The years 1982-1994 saw SCiP settle into a comfortable routine. By 1982, the Psychonomic Society had comfortably adapted to moving the meeting around the United States, and SCiP successfully followed suit, wisely electing to maintain and enhance the important relationship with the Psychonomic Society. Sidowski (1990) reports that for five of the years from 1982 through 1988, no invited speakers appeared before the Society. However, the practice of having a presidential address continued, and many of the Presidents from that era are true luminaries 
in the field. It was also during this era that women first assumed positions of leadership, with Cynthia Null serving as SCiP's first female president in 1987.

\section{The Cenozoic Era (1994-Present): The Webs We Weave}

The World-Wide Web. By 1994, Tim Berners-Lee had released the first version of the WWW protocol, and the browser Mosaic was in circulation. The world was beginning to use the Web, and SCiP was in the forefront. The first SCiP presentations on the use of the Web by research psychologists occurred in 1994 with a symposium organized by Michael Levy called "Mosaic and the Information Superhighway: A Virtual Tiger in Your Tank." In addition to Levy's (1995) overview, it included presentations on "Linked Gopher and World-Wide Web Services for the American Psychological Society and Hanover College Psychology Department” by John Krantz (1995); "Information on the Internet: How Selective Should We Be?" by Allan and Kostenbader (1995); and "Creating a Hypertext Markup Language Document for an Information Server" by Chu, Palya, and Walter (1995). The following year, I organized a symposium on psychology and the WWW. Today the membership of SCiP includes the recognized world leaders in the use of the Web in psychological research, and we have made noteworthy contributions to new Web interfaces, the practice of Web-based learning, and Web-based psychological interventions.

Survival of the fittest platform. This was also a period of Darwinian struggle among microcomputer platforms and the demise of Apple computer was a perennial prediction at SCiP conferences. As a "Macoholic," I felt that the Mac increased my productivity by allowing me to get the computer to do what I wanted without a lot of fooling around. However, there was always a lot more software for the PC, and Mac users were not always able to make use of the wonderful software for psychologists that was often available for free. At this writing, both platforms appear to be going strong, and the issue for psychologists is not so much the manufacturer as the rapid onslaught of new versions of operating systems and new chips. It seems as if no sooner has a SCiP member figured out how to "really" measure reaction times accurately, than everything changes except the unsubstantiated claims of the industry and the need for someone to learn how to do the experiment right.

The out of reach becomes affordable. This era has also seen many technologies that were once exotic mass produced and made affordable. For example, many cognitive psychologists were intrigued by the early work on eye tracking that occurred in only a handful of labs in the 1980s. Today, it might be possible to sweet talk a department chair into ponying up for an eye-tracking system without external funding. Today, we think nothing of presenting moving images as stimuli and think nothing of backing up a gigabyte of data on a thumb drive. In all of these cases, the innovations of earlier decades were brought into ordinary laboratories with SCiP leading the way. This is significant because science is advanced less by newsworthy breakthroughs than by the steady accretion of reliable knowledge.

\section{SCiP Presidents 1972-2007}

Table 1 lists the individuals who have served with distinction as presidents of the organization from 1972 to the present (with president-elect noted). I am indebted to Sidowski (1990) for compiling the early data. It is interesting (and for me personally humbling) to note how many of the early officers who were at the top of the field at the time went on to distinguished careers in psychology.

\section{Secretary/Treasurers 1974-2007}

It is a great honor to serve as President of the Society, but the most demanding job is Secretary/Treasurer. She or he is the real face of the organization, generally serving for a 3-year term, responsible for routine correspondences as well as the minutes and, of course, the organization's finances. The low cost of membership and the conference, and our sound financial footing, are directly attributable to the hard work of the following individuals who have served as Secretary/Treasurer over the years: Richard Millward, Daniel Klinger, Cynthia Null, David Eckerman,

Table 1

Presidents of the Society for Computers in Psychology

\begin{tabular}{ll}
\hline Year & \multicolumn{1}{c}{ President } \\
\hline 1972 & Donald Tepas \\
1973 & Donald Tepas \\
1974 & William Uttal \\
1975 & Joseph Sidowski \\
1976 & Lee Gregg \\
1977 & Peter Polson \\
1978 & Richard Millward \\
1979 & Daniel Bailey \\
1980 & N. John Castellan \\
1981 & John Cotton \\
1982 & Russell Church \\
1983 & Alan Lesgold \\
1984 & Geoffrey Loftus \\
1985 & Dominic Massaro \\
1986 & Walter Schneider \\
1987 & Cynthia Null \\
1988 & Earl Hunt \\
1989 & Cynthia McDaniel \\
1990 & David Eckerman \\
1991 & Jonathan Vaughan \\
1992 & Darrell Butler \\
1993 & Doris Aaronson \\
1994 & Paula Goolkasian \\
1995 & William Palya \\
1996 & Michael Levy \\
1997 & Margaret Anderson \\
1998 & Douglas Eamon \\
1999 & John Krantz \\
2000 & Walter Beagley \\
2001 & Sarah Ransdell \\
2002 & David Washburn \\
2003 & Curt Burgess \\
2004 & Robert Proctor \\
2005 & Christopher Wolfe \\
2006 & Ulf Reips \\
2007 & Roman Taraban (President-Elect) \\
\hline &
\end{tabular}


Jonathan Vaughan, Paula Goolkasian, Douglas Eamon, Sarah Ransdell, Chris Cosby, Christopher Wolfe, Katja Wiemer-Hastings, and Kay Livesay.

\section{Personal Highlights}

Symposium: Psychology and the World-Wide

Web. In 1995, I was co-primary investigator with a team that had just earned a large NSF grant for "Project Dragonfly: An Alliance of Scientists, Teachers, and Children for Elementary Science Education," and I was eager to exchange views with others working on the still fledgling World-Wide Web. I organized a symposium titled Psychology and the World-Wide Web (Wolfe, 1995b) and presented a paper, “The Dragonfly's Web: Courseware for Children Created by College Students on the World-Wide Web" (Wolfe, 1995a; Wolfe \& Myers, 1996). Arguably, the more sensible thing for me to have done would have been to present my work to an education conference, but I have always identified myself as a research psychologist and I was primarily interested in learning about what other psychologists were doing on the Web.

This was long before Google, even before Lycos and Yahoo were private companies, when their predecessors were at Carnegie Mellon and Stanford, respectively. Scott Mainwaring, then a graduate student at Stanford, presented a comprehensive collection of links to Web sites pertaining to psychology and psychological research. His talk was entitled "Compilation and Use of a World-Wide Web Index of Cognitive and Psychological Science Resources" (Mainwaring, 1996). It is hard to believe that at that time it was still possible to compile such an index by hand when today Google returns about 62 million hits for the search term "psychology."

In my abstract for the symposium I said

The World-Wide Web (WWW) is likely to have a major impact on many aspects of psychology including scientific communication, peer-refereed scientific journals, the teaching of psychology, and developing advanced applications. Eight papers are presented on the WWW and compiling mental health and psychological resources, creating psychology tutorials and courseware, creating a peer-reviewed journal, Common Gateway Interfaces (CGIs), and the Virtual Reality Modeling Language.

Jim Keiley's (1995) talk “CGIs: Gateways to WWW Power" opened my eyes to the possibility of conducting truly controlled psychology experiments on the Web. It would be a few years before SCiP members such as Michael Birnbaum, Tom Buchanan, John Krantz, Kenneth McGraw, Ulf Reips, William Schmidt, and John Williams would raise the bar and become the leading experts in the field of Web-based experimentation. John Krantz's talk "Creating Psychological Tutorials on the World-Wide Web" (Krantz \& Eagley, 1996) and my talk highlighted the potential of the Web as a medium for teaching and learning.

David Rumelhart clearly explains connectionism in mathematical terms. At the SCiP meeting in San Francisco in 1991, David Rumelhart gave an invited address to what I recall was a standing room only audience.
He started out by saying that too many people viewed connectionism as mysterious. He reasoned that we, as psychologists, understood the mathematics behind regression and that connectionism could be made less mysterious by understanding the similarities and differences between least squares regression and parallel distributed processing. For almost an hour, he gave a mathematical talk both lucid and enlightening, at times even riveting. I still believe that connectionist models have too many free parameters for my comfort, but I walked away from that address convinced that Rumelhart had a mind of the highest order, and that the approach he was taking is mathematically sound.

Stevan Harnad and a panel debate "freeing" the journal literature by making it available online. In the year 2000 in New Orleans, Stevan Harnad gave a very different talk and debated a panel about "freeing" the journal literature by making it available to everyone at no cost online. Harnad's basic argument is that scholars and scientists create the journal literature, peer review the literature, and edit the literature free of change. We are then held hostage by the publishing companies who demand copyright and make us, and our institutions, pay for the privilege of accessing that literature. The journal editors and representatives on the panel generally did not agree. They pointed out that the companies publishing journals contribute a lot more than typesetting, and that these businesses often provide valuable services to academics at the margins of financial viability. I think everyone came away with a better appreciation of the complexities of the issue. It may be that the technology, the industry, and the academy itself are too much in flux right now to make meaningful predictions or grand pronouncements about the future of the literature.

The Presidential Address. Previous SCiP presidents have set the bar high for those of us faced with the daunting task of delivering a presidential address. I honestly do not think I can remember a bad address, and some afforded excellent opportunities to learn about fascinating areas outside the scope of my own research. Two come immediately to mind. John Krantz (2000) gave a talk called "Tell Me, What Did You See? The Stimulus on Computers." Computer monitors are ubiquitous, and using them to present stimuli is a reasonable temptation. However, issues of consistency, calibration, and the like are serious matters for those studying perception and cognition. Krantz talked through the problems and solutions with great aplomb and I recommend his $B R M I C$ piece to anyone using computers for these purposes.

Past President David Washburn may be the only person in history to create video games strictly for monkeys. In "The Games Psychologists Play (and the Data They Provide)," Washburn (2003) outlined what we can learn from games. He related the story of how he was faced with the problem of enriching the environment for the primate colony at Georgia State and came across video games as a way to mentally engage the primates. Over time, he adapted the hardware and then wrote the code for new games that were more in line with the cognitive and per- 
ceptual abilities of this special population. He found solid measurable improvements in the health and well-being of these animals as a result of their interactions with these games. Of course, a layperson might be tempted to believe that the monkeys were karmically absorbing IQ points lost by Homo sapiens playing games on Homestar Runner; but we psychologists know better.

\section{Observations}

A small conference becomes more intimate. SCiP has always been a small conference, but it has not always been warm and friendly. I became involved in the governance of the organization after I opened my big mouth at the business meeting. I had given a talk at one of three concurrent sessions, and the audience barely exceeded the number of presenters. Yet the session and conference were run as if we were speaking to a full house. At the business meeting, I noted that as a tenured professor I did not need to come halfway across the country to speak to an empty room. I felt that we had assembled some of the best people working at the intersection of computers and psychology, yet we were not interacting with one another. Those present on the steering committee agreed, and we began to think of ways to increase interactions among conference attendees. Some approaches, such as SCiP lunches and putting the refreshments with the posters, have worked very well, but they are possible only if the conference hotel is conducive. There is discussion of building interest group lunches into the conference, which sounds like a good idea to me. I think that most of us have come to see the small size of the conference as a virtue, and in recent years, the atmosphere at SCiP has become much more open and intimate.

Conducting scientific research with consumergrade electronics. We are all fascinated by high-tech equipment such as brain imaging technologies, and some SCiP members are working on the "bleeding edge" of technology. Indeed I remember an excellent "Symposium on Brain Imaging Methodology for the Study of Cognitive Psychology" organized by Walter Schneider in 1992. But if we are honest with ourselves, we should acknowledge that much of the business of SCiP involves finding ways to conduct top-notch scientific research with consumergrade electronic equipment. Perhaps former BRMIC editor Jonathan Vaughan said it best when he remarked,

When we use computers, video monitors, keyboards, and videocams in our research we are using equipment designed to meet the needs of the average consumer. Thus, we confront challenges and sources of error in the areas of timing and stimulus control that are attributable to the equipment because we are trying to conduct professional-grade scientific research using consumer-grade electronic equipment. (J. Vaughan, personal communication, June 23, 2005)

Examples include numerous studies on millisecond timing of presenting stimuli and recording behavior, such as "Self-Validating Presentation and Response Timing in Cognitive Paradigms: How and Why?" (Plant, Hammond,
\& Turner, 2004). The John Krantz (2000) address "Tell Me, What Did You See? The Stimulus on Computers" is another good example. Finally, if one is interested in using the mouse in scientific research, an excellent starting place is "How Choice of Mouse May Affect Response Timing in Psychological Studies" (Plant, Hammond, \& Whitehouse, 2003). I contend that work of this kind is ultimately more valuable to the field than that performed on expensive, cutting-edge apparatus. There are literally thousands of personal computers in psychology for each fMRI device in operation.

An increasingly international organization. Over the years, SCiP has become an increasingly international organization. For example, Ulf Reips is the first European (and I believe the first non-North American) to become president of the Society. Moreover, at the 2005 meeting, presentations were accepted from half a dozen countries around the world. This most welcome trend is providing opportunities for innovation and cross-fertilization. Meeting researchers from different countries has been a highlight of my SCiP experience. During the spring of 1999, I was able to build on relationships started at SCiP and spend part of a sabbatical with a visiting appointment at the Centre for Technological Innovation in Psychology, University of York, England. I found working with European psychologists such as Nick Hammond, Annie Trapp, and Richard Plant invigorating, and I hope that we can facilitate such exchanges for more researchers in the future. Allowing members to pay dues and register online are important mechanisms for facilitating international participation.

The importance of inclusiveness. SCiP has always been open to participation from across the board, but we must continue to work at being more inclusive. A key strength is that graduate students have always been welcome. Most of us with some gray in our hair freely acknowledge that the graduate students are closer to some of the emerging technologies than we are (and are often more willing to log the hundreds of hours necessary to apply new technologies to psychological purposes). As I have already noted, the organization is increasingly open to international colleagues. Women continue to provide leadership in the steering committee, although only $18 \%$ of our presidents have been women, which is not good enough. We need to find ways to make the Society more attractive to African Americans, perhaps by partnering with relevant organizations.

\section{From Middle Age to Old Age: Integrity Versus Despair}

In Erik Erikson's thinking, the final stage of personality development in old age revolves around the conflict of integrity versus despair. Three issues will determine how we respond to this conflict: basic viability, the future role of face-to-face conferences, and the overall integrity of the Internet.

Will SCiP remain viable? There are two keys to the long-term viability of the organization: (1) the quality of the conference; and (2) everything else. SCiP must con- 
tinue to attract good papers and stellar keynote speakers. I believe that the relationship with the Psychonomic Society has been mutually beneficial, and we must work to ensure that both organizations benefit from the association. Becoming more inclusive, developing a stronger presence on the Web, and nurturing an open atmosphere are all important to our success.

As budgets shrink, and colleges and universities demand more of faculty, SCiP needs to continue to find ways to make membership more meaningful. The major activity has always been the conference, which is appropriate. However, we now see our goal as providing many valueadded services for members in addition to the conference. In recent years, we combined annual dues with conference registration fees. SCiP now offers journal discounts on relevant scientific journals, and we are experimenting with new methods for increasing the value of being a SCiP member such as creating a mechanism for SCiP members to share their expertise in computers in psychology as Web-listed consultants. I believe that these supplementary efforts are critical to the long-term health and vitality of the organization. A large portion of academic psychologists will retire in the next 5-10 years. For SCiP to thrive, we must make membership as valuable as possible.

Why FTF is important in an era of videoconferencing. I have already said that SCiP has become an increasingly intimate conference, and I believe that we need to continue to move in that direction. In recent years, state budgets have shrunk, and colleges and universities have come under increasing attack. Next year, for example, aid from the state of Ohio to my institution, Miami University, will shrink to less than $10 \%$ of its annual operating budget. The remainder must be made up by tuition, external grants, and other sources. Faculty travel and professional development are likely to face further setbacks for the foreseeable future.

Videoconferencing is an attractive alternative, and we should experiment with the possibilities of hosting and facilitating videoconferencing. However, although it is possible to use the Web to deliver scientific content, providing opportunities for informal exchanges and building relationships via videoconferencing has remained elusive. There has been discussion in the steering committee that we should head toward a cycle of face-to-face meetings in the fall, and some kind of more targeted Internet-based videoconference in the spring. I applaud the movement in this direction and believe that we will thrive as long as we continue to experiment.

The tyranny of ass-hats: Hackers, viruses, spyware, spam, smut, and ads. I first learned the term "ass-hat" on a long car trip when my wife had us listen to The Sweet Potato Queens' Field Guide to Men: Every Man I Love Is Either Married, Gay, or Dead (Browne, 2004). Urbandictionary .com (2005) defines an ass-hat as "One whose head is so far up their rear end it could pass for a hat." In my opinion, "ass-hat" nicely characterizes the people who are making the Internet less useful and less fun by hacking into Web sites and creating viruses, spyware, spam, pop up ads, and pornography.
I will illustrate with two specific examples of the consequences of ass-hat behavior. First, in the fall of 2005, in the months leading up to the conference, the SCiP Web site (http://SCiP.ws) was attacked by malicious hackers who vandalized the site and destroyed all of the data. This stupidity wasted the time of people such as Web master Xiangen $\mathrm{Hu}$, who works on the Web site as a labor of love. The hackers destroyed our ability to collect advance registration fees online and delayed communication of time-sensitive materials. Second, in our own research on a Web-based intervention to help families of children with traumatic brain injury (TBI; Wade, Wolfe, Brown, \& Pestian, 2005; Wade, Wolfe, \& Pestian, 2004), participating families had a devil of a time with the Sobig virus and spyware. The intervention gave families of children with TBI computers, high-speed Internet access, and Web cams to test the efficacy of a Web-based intervention. Participating families came from all walks of life and varying levels of computer experience (e.g., parental occupation ranged from lawyer to janitor). The project staff and participating families had to wrestle with spyware and viruses on top of learning the technology and confronting the presenting issues associated with TBI. That the projects proved successful is a testament to all involved.

It should not be this way! In my experience, the Internet is actually less useful than it was 5 years ago. The dominant cultural narratives of computerization speak of unending progress (and the primary counternarrative is one of dehumanization). Neither of these adequately expresses the realities of contemporary networked computing. Computers are becoming faster, and some of the software that we use is becoming more useful; but what used to be minor annoyances are becoming increasingly debilitating. The future viability of the Internet for research and teaching depends critically on whether or not we are able to overcome hacking, viruses, spyware, spam, smut, and ads (not to mention the next set of problems, whatever they may be). These problems are clearly larger than SCiP, but in some respects they affect us disproportionately. My fear is that as the ass-hats raise the personal, emotional, and financial cost of using computers, those working in a not-for-profit capacity will be hit the hardest. Who wants to create and share software and other Internet-accessible resources if the result is grief and aggravation?

\section{My Crystal Ball: Conclusions}

I predict continued success for the Society for Computers in Psychology. We have a good group of people currently involved with the organization, including some bona fide rising stars. Many of us who are less than household names have been generous in donating time and talent. If we can continue to attract good papers, innovate with new technologies, provide new services for our members, make our meetings increasingly interactive, and fend off the ass-hats with ingenuity and a sense of humor, then I see no reason why SCiP should not stick around long after I retire. So if you happen to find yourself organizing the 50 th, 60th, or 70th meeting of the Society, shoot me an electronic hologram or something. In the finest traditions 
of SCiP, I'll do my part by providing a high technology rendering of the gluteus maximus of a Macaca mulatta.

\section{REFERENCES}

Allan, R. W., \& Kostenbader, P. S. (1995). Information on the Internet: How selective should we be? Behavior Research Methods, Instruments, \& Computers, 27, 198-199.

Browne, J. C. (2004). The Sweet Potato Queens' field guide to men: Every man I love is either married, gay, or dead. New York: Three Rivers Press.

Chu, J. Y. M., Palya, W. L., \& Walter, D. E. (1995). Creating a hypertext markup language document for an information server. Behavior Research Methods, Instruments, \& Computers, 27, 200-205.

KeILey, J. (1995, November). CGIs: Gateways to WWW power. Paper presented to the Society for Computers in Psychology, Los Angeles.

KrantZ, J. H. (1995). Linked Gopher and World-Wide Web services for the American Psychological Society and Hanover College psychology department. Behavior Research Methods, Instruments, \& Computers, 27, 193-197.

Krantz, J. H. (2000). Tell me, what did you see? The stimulus on computers. Behavior Research Methods, Instruments, \& Computers, 32 , 221-229.

Krantz, J. H., \& Eagley, B. M. (1996). Creating psychological tutorials on the World-Wide Web. Behavior Research Methods, Instruments, \& Computers, 28, 156-160.

LEvy, C. M. (1995). Mosaic and the information superhighway: A virtual tiger in your tank. Behavior Research Methods, Instruments, \& Computers, 27, 187-192.

Mainwaring, S. D. (1996). Compilation and use of a World-Wide Web index of cognitive and psychological science resources. Behavior Research Methods, Instruments, \& Computers, 28, 152-155.

Plant, R. R., Hammond, N., \& Turner, G. (2004). Self-validating presentation and response timing in cognitive paradigms: How and why? Behavior Research Methods, Instruments, \& Computers, 36, 291-303.

Plant, R. R., Hammond, N., \& Whitehouse, T. (2003). How choice of mouse may affect response timing in psychological studies. Behavior Research Methods, Instruments, \& Computers, 35, 276-284.

SidowsKi, J. B. (1990). Past, present, and future of the Society for Computers in Psychology. Behavior Research Methods, Instruments, \& Computers, 22, 94-97.

Urbandictionary.com (2005). Available on the Web 6/24/05 at www .urbandictionary.com/define.php?term=ass-hat.

Wade, S. L., Wolfe, C. R., Brown, T. M., \& Pestian, J. P. (2005). Putting the pieces together: Preliminary efficacy of a Web-based family intervention for children with traumatic brain injury. Journal of Pediatric Psychology, 30, 437-442.

Wade, S. L., Wolfe, C. R., \& Pestian, J. P. (2004). A Web-based family problem-solving intervention for families of children with traumatic brain injury. Behavior Research Methods, Instruments, \& Computers, 36, 261-269.

WASHBurn, D. A. (2003). The games psychologists play (and the data they provide). Behavior Research Methods, Instruments, \& Computers, 35, 185-193.

Wolfe, C. R. (1995a, November). The Dragonfly's Web: Courseware for children created by college students on the World-Wide Web. Paper presented to the Society for Computers in Psychology, Los Angeles.

Wolfe, C. R. (1995b). Psychology and the World-Wide Web. Symposium organized for the Society for Computers in Psychology, Los Angeles.

Wolfe, C. R., \& Myers, C. A. (1996). The Dragonfly's Web: Courseware for children created by college students on the World-Wide Web. Behavior Research Methods, Instruments, \& Computers, 28, 161-164.

(Manuscript received November 14, 2005; revision accepted for publication December 13, 2005.) 